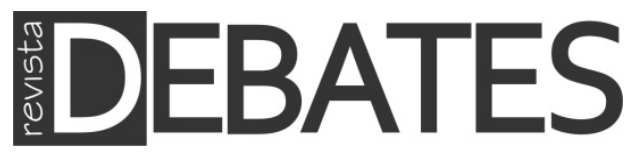

\title{
Regionalismo e desenvolvimento na América do Sul
}

\author{
Regionalism and development in South America
}

\section{Leonardo Granato Ian Rebouças Batista}

\section{Resumo}

O objetivo do presente trabalho é discutir os diferentes modos de entender o desenvolvimento periférico que tiveram expressão nas variadas experiências de integração na América do Sul a partir de meados do século XX. Buscamos, em um primeiro momento, entender os significados atribuídos pela literatura à integração regional, bem como à noção de desenvolvimento. Em um segundo momento, analisamos a trajetória do regionalismo sul-americano à luz dos conceitos e ideias trabalhados na seção anterior, evidenciando uma prevalência da noção de desenvolvimento exógeno nas experiências integracionistas. Concluímos que, apesar de que com o tempo a noção de desenvolvimento tenha evoluído para um conceito muito mais complexo do que o mero crescimento econômico, o olhar mercantilista e liberal tem predominado nos objetivos dos processos integracionistas sul-americanos.

\section{Palavras-chave}

Integração Regional; Desenvolvimento; América do Sul.

\begin{abstract}
The objective of this paper is to discuss the different ways of understanding the peripheral development that have been expressed in the varied experiences of integration in South America from the middle of the XX century. We seek, at first, to understand the meanings attributed by the literature to regional integration, as well as the notion of development. In a second moment, we analyze the trajectory of the South American regionalism considering the concepts and ideas worked in the previous section, evidencing a prevalence of the notion of exogenous development in the integrationist experiences. We conclude that, despite the fact that over time the notion of development has evolved into a much more complex concept than mere economic growth, the mercantilist and liberal outlook has predominated in the objectives of South American integration processes.
\end{abstract}

\section{Keywords}

Regional Integration; Development; South America. 


\section{Introdução}

A partir da segunda metade do século passado até os dias atuais, a integração regional ${ }^{1}$ na América Latina tem se mostrado, em diferentes períodos e com distintas abordagens, como uma alternativa de política estatal para a perseguição de determinados objetivos de desenvolvimento. Duas consideraçóes preliminares merecem ser efetuadas a esse respeito.

A primeira delas é que a integração regional latino-americana, enquanto expressão de política estatal, não pode ser analisada desconsiderando seu contexto: a expansão do capitalismo e a hegemonia do pensamento neoliberal. No referido contexto, historicamente, existiram diferentes formas de conceber a integração regional na América Latina, seja como manifestação de uma sociedade centrada no mercado, seja como "reação" à expansão capitalista e ao entendimento de que tal sistema apenas garantiria o atraso dos países mais pobres com relação aos países mais poderosos.

A segunda questão, organicamente vinculada à anterior, tem a ver com o fato de a integraçáo regional ter funcionado historicamente como instrumento de desenvolvimento dependente ou autônomo, a depender dos objetivos de política externa e econômica que se formulem ${ }^{2}$. Não resulta difícil visualizar como a disputa entre a ofensiva neoliberal e o keynesianismo, a partir do pós-Segunda Guerra, se refletiu nas primeiras experiências latino-americanas de integração. Através da dicotomia entre aqueles que defendiam uma política de integração baseada no princípio de livre comércio (que por sua vez possuía como objetivo tornar-se funcional à liberalização promovida pelas instituiçôes multilaterais internacionais) e aqueles que reafirmavam a importância de uma solidariedade estratégica no Terceiro Mundo, com objetivos de desenvolvimento (econômico, social e cultural) e de uma inserção não subordinada no sistema internacional. Essa dicotomia dependência-

\footnotetext{
1 O termo "integração" faz parte da linguagem corrente das ciências sociais, sendo empregado indistintamente no âmbito de diferentes disciplinas para expressar o comum ideal para unir as partes separadas de um universo. No âmbito da Ciência Política e Relações Internacionais latino-americanas, campo no qual se inscreve o presente trabalho, a integraçáa regional, ou regionalismo, é entendido como um projeto político interestatal que "pressupóe a formação de um espaço econômico integrado e coordenação regional de políticas públicas” (SOARES DE LIMA, 2013, p. 178).

${ }^{2}$ Em oposição à ideia de desenvolvimento dependente associado aos centros hegemônicos externos, com desenvolvimento autônomo estamos nos referindo àqueles enfoques que supóem que os países latino-americanos, colocados na periferia do capitalismo, podem aperfeiçoar, ainda que sempre de forma relativa, certa autonomia de decisão para almejar o desenvolvimento (GRANATO e BATISTA, 2017 e 2018a).
} 
autonomia, assim como a superação da noção de desenvolvimento como mero crescimento econômico (SOARES, 2016), têm marcado a trajetória dos regionalismos no continente até hoje, momento em que, de fato, estamos assistindo os debates sobre a mudança de rumo do Mercosul, por exemplo, em virtude da "virada conservadora" operada na América do Sul.

Feitas tais consideraçôes, propomos a seguir uma reflexão teórica acerca da integração regional como instrumento estatal de desenvolvimento no continente. Dessa forma, buscamos, em um primeiro momento, entender os significados atribuídos pela literatura à integração regional periférica, bem como à noção de desenvolvimento. Em um segundo momento, à luz dos conceitos estudados, analisamos a trajetória dos ciclos da integração regional, com destaque para América do Sul.

\section{Integração e desenvolvimento em discussão}

A história da integraçáo latino-americana é concomitante ao surgimento dos Estados nacionais independentes da região. Desde suas formaçôes, os Estados da regiáo recorrem à esfera regional para perseguir objetivos políticos internos. É ainda no século XIX que a proposta de Grande Colômbia de Simón Bolívar se apresenta como possibilidade de os países recém-nascidos enfrentarem melhor sorte no cenário internacional. $\mathrm{O}$ objetivo era que a cooperação regional, assim como o direito internacional, consolidasse o direito de regência desses novos Estados (PETERSEN e SCHULZ, 2018), o que reflete um interesse particular do momento de formaçáo dos Estados nacionais, a busca pela legitimidade (KAPLAN, 1990; LECHNER, 1981).

$\mathrm{Na}$ virada do século XIX para o XX a região contava os corpos e os prejuízos da Guerra do Paraguai. Surge nesse momento a preocupaçáo com a pauta da segurança na região, e as maneiras de garanti-la através de tratados de cooperação regional. Argentina, Brasil e Chile, principais potências sul-americanas à época, negociam o Tratado de Cordial Inteligência Política e de Arbitragem, voltado para a paz regional e entendido como condição necessária para o fortalecimento econômico (BARNABÉ, 2012). A proposta, que não foi assinada ou posta em prática, também pode ser compreendida como um primeiro movimento contrário à influência hegemônica na região, almejando autonomia para uma política de defesa comum dentre países da região.

Concomitantemente, o Pan-Americanismo era a ideologia difundida pelos Estados Unidos àquele momento, que ascendia como potência hegemônica mundial. 
Como reflexo da difusão desse ideal, Petersen e Schulz (2018) sustentam que parte das elites periféricas se interessava em bons laços com os Estados Unidos, dado que serviria como incrementaçáo da almejada legitimidade desses Estados. A própria agenda regional pan-americanista, nesse período, marcada pela flexibilidade das pautas, apresentava questóes sociais, como conferências e reunióes sobre serviços públicos, aviação civil, práticas bancárias, telecomunicaçóes e infraestrutura (PETERSEN e SCHULZ, 2018).

A crise que as oligarquias latino-americanas enfrentavam internamente, no que tange a legitimação dos Estados-nacionais, encontrou na cooperação regional um instrumento para consolidação de seu aparato e, consequentemente, autonomia na gerência do Estado. Recapitulemos a proposta de Simón Bolívar, do século XIX, frequentemente apontada como um primeiro sopro de aspiraçáo autonomista na região, principalmente por se tratar de um movimento contrário às elites europeias colonizadoras. Sua tentativa era de legitimar o aparato estatal-nacional, o que implicava, ao fim e ao cabo, a cristalização de uma elite local no topo da cadeia de dominação do Estado. Autonomia, muitas vezes significa, assim, a busca pela consolidação da dominação de uma elite local, e não estrangeira. Entendemos aqui, contudo, que a gerência de uma elite local no Estado é mais sujeita e propícia a atender as necessidades da população ${ }^{3}$.

Esse esclarecimento torna-se necessário nesse momento, pois, na sequência de nossa argumentação, emergem no pós-Segunda Guerra o embate ideológico do keynesianismo e o neoliberalismo. Como ambas as ideologias disputavam a influência dos governos na América Latina, a integração regional também refletia esses distintos entendimentos de mundo. A integração passa a ser considera pelos países como um instrumento para o desenvolvimento, e o embate ideológico definirá quais os termos de perseguição desse desenvolvimento. Quando falarmos em integração como instrumento para autonomia, teremos uma visão mais próxima do keynesianismo, heterodoxa, preocupados com o aquecimento da economia e com a redistribuição de renda para tanto. Quando a integração almejar a conexão das malhas produtivas e

\footnotetext{
${ }^{3}$ Entender o objetivo de autonomia como consolidação de uma elite local na gerência do Estado é fundamental para entendermos que as disputas ideológicas que pautam tanto os governos quanto a integração se referem ao modo de produção capitalista. Essas disputas não são pela real libertação dos povos ou pelo fim da dominação. As alternativas discutidas nesse trabalho se tratam de possibilidades dentro do sistema capitalista. Nesse cenário, contudo, entende-se que a autonomia almejada por Bolívar e, na sequência, por Furtado e Jaguaribe, por exemplo, podem vir a possibilitar melhores chances às camadas populares da sociedade civil.
} 
ampliação do acesso a mercados, exclusivamente, a influência mais nítida é a do neoliberalismo, interessados em um mundo sem fronteiras, de livre circulaçáo do mercado.

Similarmente ao que ocorria na integraçáo europeia, na qual encontrávamos uma "Europa-mercado" e uma "Europa-comunidade" (LANÚS, 1972, p. 36), esta dicotomia também se expressou na primeira onda de propostas de regionalismo latino-americano dos anos 1960, cujos países envolvidos identificavam a integração como mecanismo de liberalizaçáo comercial, restringindo o papel do Estado à eliminação de barreiras ao comércio.

Pautando a agenda e os objetivos desses blocos, a grande influência intelectual era a produção da Comissão Econômica para a América Latina (CEPAL). Órgão da Organização das Naçôes Unidas, a CEPAL reuniu economistas da região para pensarem o subdesenvolvimento e a possibilidade de superá-lo, e, assim, as reflexôes que se desencadearam foram estimuladas, fundamentalmente, pela tomada de consciência do atraso econômico latino-americano (SUNKEL e PAZ, 1970). Nesse aspecto, Rodriguez (1986) admite que o grande mérito da CEPAL foi a construção de um aparato teórico coeso e bem articulado que justificava o subdesenvolvimento da periferia. O diagnóstico da referida Comissão era de que sendo as economias latinas exportadores de matérias-primas fortemente dependentes da demanda externa, a solução devia ser buscada na industrialização substitutiva de importaçôes conduzida pelo Estado.

A liderança da CEPAL estava a cargo do economista argentino Raúl Prebisch, responsável por conceber o núcleo do estruturalismo latino-americano, nomenclatura pela qual ficou conhecida a teorização do sistema centro-periferia cepalino. A leitura do subdesenvolvimento da América Latina e as propostas para superação dessa condição são frequentemente associadas a um projeto reformista de longo prazo, que ganhou relevância intelectual ao romper com a ideologia liberal até entáo difundida e aplicada pelas oligarquias agrárias da região (TORRES RIVAS, 1987).

Contudo, apesar da conduçáo macroeconômica do Estado e do foco no aquecimento do mercado interno e na produtividade (acumulação e progresso das técnicas), cabe apontarmos aqui que o pensamento cepalino náo pode ser associado com um keynesianismo de cartilha. Como aponta Pedro Fonseca (2000), as aproximaçóes entre Prebisch e Keynes são apenas aparentes. Prebisch e a CEPAL atribuíram determinante peso à variável tecnológica para o desenvolvimento, assim como desenvolveram a teoria da deterioração dos termos de troca e dos salários. Esses 
aspectos significam análises, investimentos e políticas de longo prazo. Por sua vez, o keynesianismo se preocupa muito mais com o curto prazo. Distinguir o pensamento cepalino do keynesiano é crucial para entendermos a guinada ortodoxa assistida pela organização na década de 1990, quando reinterpretará as políticas desenvolvimentistas, em geral, e integracionistas, em particular, sugeridas para a região.

Na década de 1960 ainda, a integração regional assumiria para a CEPAL o papel de regionalizar o processo de substituição de importaçóes, melhorando o funcionamento e a estrutura do setor industrial latino-americano. $\mathrm{O}$ regionalismo apresentava-se a serviço do desenvolvimento, endogenamente entendido (CEPAL, 1959), como oportunidade de ampliação dos mercados nacionais, de superação das limitaçóes produtivas da malha industrial de cada país e de potencializar o financiamento e investimento para produção de novos bens (ILPES, 1967).

A partir da contribuição da referida Comissão, foi se consolidando, também, um pensamento que entendia a integraçáo como um projeto político, como uma "ação política" (ARAGÃO, 1969, p. 56), e não simplesmente como uma "mera fórmula” ou instrumento gerencial de mercados (LANÚS, 1972, p. 34). O próprio Furtado, integrante da equipe comandada por Prebisch na CEPAL, qualificaria a integração regional como uma "forma avançada de política de desenvolvimento" (FURTADO, 1967, p. 254) e ao próprio desenvolvimento como um conceito que além de crescimento econômico refere-se à satisfação das necessidades elementares da população (FURTADO, 1980).

Com base na tradição cepalina, ideias também foram gestadas no pensamento social, destacando-se particularmente na década de 1960, autores como José Vasconcelos, José Ingenieros, Alfredo Palacios, Víctor Haya de la Torre e José Carlos Mariátegui, entre outros, que, resgatando o pensamento social do final do século XIX, privilegiavam a unidade latino-americana, como a reivindicação de igualdade, de independência e do "autônomo"; os teóricos da "dependência", com aportes de Fernando Henrique Cardoso, Theotonio dos Santos, André Gunder Frank e Ruy Mauro Marini, entre outros, e na década de 1970, a chamada teoria da autonomia. Este último movimento, liderado por Juan Carlos Puig na Argentina e por Helio Jaguaribe no Brasil, propiciou, em linhas gerais, diversas análises sobre a situação latino-americana no contexto mundial, sobre a assimetria existente na relação América Latina-Estados Unidos, assim como sobre a necessidade de ponderar o contexto regional como parte da estratégia que deveria ser adotada pelos países latinos 
que buscavam o desenvolvimento e a inserção internacional em um mundo bipolar (BERNAL-MEZA, 2015).

Ao definir autonomia como “a máxima capacidade de decisão própria considerando que se pode ter, levando em consideração os condicionantes objetivos do mundo real", Puig (1980, p. 149) reconhecia a possibilidade de os países periféricos "neutralizarem" a ação hegemônica dos países centrais. Conforme os preceitos formulados por Puig, os países periféricos necessitam de recursos mínimos e elites comprometidas com o processo de "autonomização" assim como de uma integração real, com países semelhantes, que permita a máxima acumulação possível de poder para sustentar o projeto de autonomia (PUIG, 1980; O'DONNELL e LINCK, 1973). Já o próprio Jaguaribe (1973, p. 64), também orientava seu pensamento em direção do chamado "modelo autônomo de desenvolvimento e integração" que permite dimensionar a importante aliança estabelecida entre desenvolvimento e autonomia (fim) e integração regional (meio). Para o autor, um desenvolvimento autônomo e um movimento autônomo de integraçáo da América Latina consistiria em processos cujas decisóes relevantes seriam tomadas por atores e agências latino-americanas, e baseados em seus próprios interesses, conforme a sua própria perspectiva e através de suas livres decisões (JAGUARIBE, 1973).

Essa construção teórico-intelectual da integração regional enquanto instrumento de desenvolvimento autônomo não encontra respaldo em propostas efetivas de regionalismo durante a segunda parte do século passado. Somente na virada do milênio, como demonstraremos na seção seguinte, esses valores assumirão as agendas das políticas regionais de alguns países sul-americanos. Em grande parte, não foram antes aplicados graças ao paradigma ideológico neoliberal vigente na região, ainda que em diferentes graus, durante os governos militares dos anos 1960, 1970 e 1980.

A própria caracterização dos governos autoritário-modernizantes, ou burocrático-autoritários, permite compreendermos a dinâmica das propostas de integração regional na América Latina na segunda metade do século passado. Em grande parte, aplicando os preceitos neoliberais, e a influência dos chamados "Chicago Boys" na economia chilena é grande exemplo, buscou-se reduzir as funçóes e o aparato estatal, desregulando a economia e possibilitando que o mercado corresse livre. De inspiração neoclássica e crente na mão invisível do mercado para ajuste dos índices econômicos, o aparato militar era compreendido naquele momento como a força física necessária para controlar a sociedade para que o capitalismo pudesse 
retomar a pujança na região (GRACIARENA, 1984) ${ }^{4}$. Além disso, era difundida também a ideologia da segurança-nacional norte-americana. Típica dos anos da Guerra Fria, tratava-se do combate internacional à influência comunista. A grande proposta de integração regional assistida durante esse período reflete, principalmente, esse último ponto. Na Aliança para o Progresso, guiados pelos Estados Unidos, os países latino-americanos adotavam uma agenda de securitização anti-comunista que possibilitou, inclusive, a emergência de várias das ditaduras assistidas na região.

Somente nos anos 1990 as elaboraçôes teóricas sobre a integração regional irão refletir a ideologia neoliberal, impulsionadas nas propostas de reforma chamada de "Consenso de Washington". O objetivo dessa "cartilha" era a construção do Estado neoliberal na América Latina, eliminando a liberdade de implementar políticas públicas que não se ajustassem aos objetivos do ajuste estrutural. Nesse contexto, o novo paradigma para entender a integraçáo regional significou uma "quebra" em relação ao espírito e ao sentido da integração regional desenvolvida por autores como Puig (1980) e Jaguaribe (1973), idealizando agora um modelo de integração que privilegiasse a dimensão comercial de abertura dos mercados nacionais.

As referidas características integravam o que, nos anos 1990, a CEPAL definiu como o que deveria ser a nova estratégia global de integração regional: o "regionalismo aberto", que conciliaria a interdependência nascida dos processos de integração regional ou de acordos comerciais de caráter preferencial e aquela nascida das forças mercantis, também chamado de multilateralismo comercial. Será em 1994 que a CEPAL aplicará explicitamente o conceito de regionalismo aberto ao contexto latino-americano, através do discurso de servir para a transformação produtiva com equidade (CEPAL, 1994), compreensível quando se considera que esse organismo nunca abraçou a heterodoxia ou se baseou no keynesianismo para propor políticas de desenvolvimento.

Os limites da orientação econômica neoliberal foram escancarados na avaliação eleitoral na virada do milênio em diversos países da regiáo. Desemprego, transferência monetária para setores rentistas (MATTEI, 2013) e ampliação da

\footnotetext{
${ }^{4}$ Cabe frisarmos que o movimento da sociedade civil que antecede os golpes militares nos países da região se refere a ebulição social e ampliação de demandas, como as reformas de base no Brasil. Dessa forma, entende-se que as ditaduras são respostas do capitalismo para restauração da ordem necessária ao funcionamento do mercado (GRACIARENA, 1984). Outro ponto que cabe comentário é o caso brasileiro, que compreende uma exceção à influência neoliberal nesse momento, pois apresenta uma economia profundamente protecionista e estadista (MATTEI, 2013).
} 
desigualdade social (OSTRY, LOUNGANI e FURCERI, 2016) são alguns dos índices econômicos e sociais que justificam as seguidas derrotas da agenda neoliberal nas eleiçôes de 2002 no Brasil, 2003 na Argentina, 2004 no Uruguai e 2005 na Bolívia, para citar apenas alguns exemplos. A ascensão de governos de centroesquerda foi chamada por David Harvey (2010, p. 198) de "uma nova forma de estadismo de esquerda", representado por uma mudança na orientação política e ideológica na América Latina, no que se refere as pretensôes de superação do dogma neoliberal (SOARES DE LIMA, 2013), e da criação de uma ordem pós-liberal (SADER, 2010).

Apesar da manifesta impossibilidade de abandonar o paradigma mercantilista hegemônico da década de 1990, novas práticas integracionistas se apresentaram na América do Sul, que foram retroalimentando-se com perspectivas teóricas que buscaram "reinventar o regionalismo para o novo século" (GARCÍA DELGADO e CHOJO, 2006, p. 123), assim como vieram nas novas práticas um modelo de desenvolvimento e inserção internacional soberano e socialmente orientado (VISENTINI, 2007; SARTI, 2017). Recuperou-se o entendimento de integração regional presentes em Furtado, Puig e Jaguaribe, contextualizando a um novo momento do cenário internacional e regional. A integração é concebida, nesta perspectiva, como um instrumento para fortalecer as capacidades nacionais e afirmar as possibilidades de autonomia, conforme o entendimento de que não constitui tarefa vã para a América Latina afirmar os valores de solidariedade e de justiça social.

Em definitivo, segundo Sarti (2017), a questáo da autonomia, diretamente vinculada à questão do desenvolvimento, é aquela dos que se preocupam com as desigualdades sociais e com a injustiça social; é a preocupação dos que não se conformam em permanecer na periferia do sistema internacional. Em suma, com a integração se pretendia, nos termos de Ferrer (2006), contribuir para o combate contra uma divisão internacional do trabalho que impede a industrialização dos países latinos, assim como a generalizaçáo de conhecimento e de tecnologia, e contar com uma suficiente liberdade de manobra, no contexto do capitalismo global, para desenhar e implementar projetos nacionais viáveis de desenvolvimento com inclusão social. Analisemos, na próxima seção, à luz dos conceitos e interpretaçóes discutidos, as trajetórias dos regionalismos com ênfase na América do Sul. 


\section{Os ciclos da integração na América do Sul e a prevalência da visão mercantilista}

De maneira geral, historicamente, os contextos nacionais e regionais na América Latina possibilitaram que os países atravessassem períodos de obstáculos semelhantes e prognósticos aproximados. Depois de alcançar a independência, e durante a primeira metade do século XIX, os países latino-americanos, que ainda não constituíam Estados nacionais consolidados e muito menos um sistema político e econômico regional, foram condicionados, com a anuência das elites locais, na periferia da geopolítica mundial (CARDOSO e FALETTO, 1973; O'DONNELL e LINCK, 1973). Estabelece-se, assim, uma relação assimétrica entre centro e periferia, através de uma variedade de tratados comerciais de caráter desigual que replicavam a relação de subordinaçáo característica do seu passado colonial. Com o passar do tempo, a consolidaçáo das classes ou alianças de classes que controlavam as estruturas produtivas exportadoras destes países - as oligarquias - precisaria reformar o Estado nacional para que se adequasse a um novo padrão capitalista de relaçóes sociais, orientado a favorecer o processo de acumulação (GRACIARENA, 1984). A problemática adveio da aparição das classes médias e populares na vida política e a ampliação da democracia formal, que introduziram no Estado latino-americano um moderado reformismo na ordem tradicional conservadora modernizante, gerando-se uma situação de permanente conflito social e instabilidade política, marcada pela ruptura da ordem constitucional e por processos ditatoriais (GRACIARENA, 1984), que se manteve durante grande parte do século XX.

Observando a partir do âmbito regional é possível falarmos em "ciclos" nos quais os países compreendiam a integração de maneiras semelhantes, de acordo com a vida doméstica desses Estados e à maneira subordinada com que estes estavam inseridos no sistema internacional. Tornou-se, assim, comum na literatura tratar dos períodos de velho regionalismo, para indicar as primeiras propostas de integração da segunda metade do século XX; novo regionalismo, ao se referir as propostas inspiradas pelo paradigma neoliberal dos anos 90; e regionalismo pós-liberal ou póshegemônico para tratar das propostas típicas dos governos de esquerda e centroesquerda que ascendem na virada do milênio (VEIGA e RIOS, 2007; RIGGIROZZI e TUSSIE, 2012; GRANATO e BATISTA, 2018a). Nesses ciclos, é possível identificarmos que as distintas abordagens de integração típicas de cada período são frutos dos contextos nacionais e internacionais específicos e que justificam o tipo de regionalismo proposto. 
Assim, quando falamos do modelo do velho regionalismo (entre as décadas de 1950 e 1980), que propunha uma integração aos moldes cepalinos desenvolvimentistas, devemos considerar que essas ideias estavam no auge de sua produção e a CEPAL se destacava como meio intelectual produtivo ao interesse de desenvolvimento latino-americano. O desenvolvimentismo e o modelo de substituição de importaçóes estavam em voga em grande parte dos governos da região. Além disso, fatores como a deterioração dos termos de troca no comércio internacional estimularam, a partir da década de 50, que determinados países latinoamericanos iniciassem um processo de integraçáo econômica, não com vias de estabelecer uma união política, mas sim como um meio em direção ao desenvolvimento interno de cada um deles (JAGUARIBE, 1973; KAPLAN, 1969). Em 1960, por exemplo, seria originada a Associação Latino-Americana de Livre Comércio (ALALC), com o objetivo de criar uma zona de livre comércio que avançaria até a criação de um mercado comum, o que criaria, em tese, estímulos para o desenvolvimento industrial sobre bases competitivas, reduzindo a dependência externa dos países membros frente ao resto do mundo (ILPES, 1967). Simbolicamente, a referida iniciativa significou um projeto emancipador, ao propor um objetivo de unidade regional visando à superação de um longo ciclo de desencontros e fragmentação (KAPLAN, 1969).

$\mathrm{Na}$ prática, contudo, a ALALC esteve longe de atingir seus objetivos. Em análise do período, Mindlin (1973) aponta as razóes que estariam levando a organização ao entrave de seu funcionamento. Apesar de ter sido recebida com empolgaçáo pelos países inicialmente envolvidos (Argentina, Brasil, Uruguai e Chile), indica que a reduzida participação dos empresariados nacionais na tomada de decisão do bloco, o escasso aproveitamento das concessôes comerciais vigentes e a gradual incorporação de novos países à organização fizeram com que esta fosse perdendo fôlego. Para lidar com os distintos interesses de países grandes, medianos e pequenos (CNI, 1969 apud MINDLIN, 1973, p. 78), a ALALC foi remodelada para a Associação Latino-Americana de Integração (ALADI), onde uma nova estrutura jurídica buscava dar renovado fôlego à integração da região. Dentre as mudanças de rumo, pode-se apontar, conforme surge da própria letra do Tratado de Montevidéu de 1980, a substituição do objetivo de liberalizaçáo econômica pelo de estabelecimento de áreas de preferências econômicas, o tratamento diferenciado para países em estágios de desenvolvimento distintos e a regulamentação recíproca e cooperação econômica como norte da proposta. Contudo, por mais que exista até os 
dias de hoje, esta organização também não avançou em seus objetivos, em grande parte pela falta de alinhamento macroeconômico comum, "o que significa a ausência de capacidade de decisão frente aos grandes problemas do intercâmbio, limitando-se a debater problemas menores de caráter técnico e diplomático" (VIEIRA, 2015, p. 53).

Os fracassos das propostas de integração do período podem, assim, ser entendidos através do contexto de exacerbado nacionalismo das ditaduras militares que assolavam a regiáo. Para Jaguaribe (1973), por exemplo, fracassaram pela ausência de uma orientação única tanto da política interna quanto da externa, assim como pela baixa interdependência entre os países que buscavam a integração - uma vez que a política externa das ditaduras latino-americanas buscava o alinhamento à potência hegemônica estadunidense e relevavam a cooperação regional com seus vizinhos. Por mais que tenha sido um período onde sugiram as primeiras contribuições sobre autonomia mencionadas na seção anterior, o contexto interno de governos autoritários e o contexto internacional, de Guerra Fria e de uma América do Sul "satelizada", possibilita entendermos o que limitou esses esforços iniciais.

De todo modo, cabe mencionar que a gênese do Mercosul começou com a redemocratização do Brasil e da Argentina em meados da década de 80, cujos governos deram importantes passos na cooperação bilateral, criando as bases para a criação gradual de um mercado comum que contribuísse para o desenvolvimento interno (através de protocolos setoriais de coordenação interindustrial) e aumentasse a capacidade de negociação na arena internacional. Conforme afirmado por Saraiva (2012, p. 57), "as percepçóes de rivalidade e disputa por uma hegemonia regional que haviam marcado as relaçóes entre o Brasil e Argentina durante muito tempo foram suplantadas por ideias de cooperaçáo e, ao final da década, por ideias de parceria”.

No segundo período chamado de novo regionalismo (década de 1990), com observância das diretrizes internacionais do regionalismo aberto, os governos da região assumiam a "cartilha" difundida pelo Consenso de Washington de desregulamentação econômica, de redução do Estado, do funcionalismo público e da liberalização dos mercados (MATTEI, 2013). Consequentemente, a integração regional (funcional a esses propósitos) foi marcada por propostas como o Mercosul e a Comunidade Andina, que redefiniram seus objetivos ao adotar um modelo de integração com abertura para os mercados externos, assumindo um caráter principalmente comercial.

Devemos considerar também que o fim da Guerra Fria possibilitou a ascensão dos Estados Unidos como único hegemon global, permitindo que tomasse a frente inclusive dos processos de integraçáo latino-americanos, com a proposta da Área de 
Livre Comércio das Américas (ALCA), sendo de interesse um mercado globalizado e liberalizado. As propostas de integração desse período ficaram marcadas pela ausência de uma agenda de integração positiva (SCHARPF, 1996), que impulsionasse políticas comuns em áreas estratégicas, tais como infraestrutura, política social e cultural, agenda esta que supostamente permitiria maior participaçáo ou interesse social ao processo de integração. Por esse motivo, até o fim da década de 1990, os processos de integração pareciam perder impulso, questão essa que seria aprofundada sob o ciclo do estancamento econômico, da mobilização social e da instabilidade política que afetou vários países da regiáo.

É na virada do milênio, acompanhada da ascensão de governos progressistas de esquerda e centro-esquerda na regiáo, que a integração regional será abordada novamente com viés autonomista e de desenvolvimento (GRANATO, 2015), no contexto do chamado paradigma pós-hegemônico, em alusão ao distanciamento dos Estados Unidos na agenda de regionalismo da América do Sul. Propostas como a Aliança Bolivariana para os Povos da Nossa América (ALBA), a União das Naçôes Sul-Americanas (Unasul) e o Mercosul "reconfigurado", tiveram como ideais basilares a visão integral da integração regional que entendia que os processos associativos não deveriam se limitar ao âmbito econômico-comercial e que deviam envolver múltiplos atores sociais além dos governamentais (PUIG, 1986). O contexto do sistema internacional também permitiu uma brecha estrutural adequada para propostas nesses moldes. Os Estados Unidos travavam a Guerra ao Terror no Oriente Médio (o que distanciou o hegemon da América do Sul), bem como o preço internacional de commodities (como o barril de petróleo cru) disparou, favorecendo boa parte dos países da região que são, primordialmente, exportadores primários. Com o distanciamento do big stick estadunidense e com crescentes somas de capital internacional, a América do Sul pôde novamente buscar uma integração que buscasse autonomia e autodeterminação de seu desenvolvimento.

Passados quinze anos do início do ciclo progressista na regiáo, já é possível também analisarmos os resultados e investigar de que formas os âmbitos internos e externos se relacionam para explicitar as causas dos possíveis sucessos e fracassos das propostas pós-hegemônicas. Para Muhr (2010 e 2011), por exemplo, a Venezuela criou e liderou a ALBA com o objetivo estratégico chavista de despontar como liderança no norte do continente e na América Central, beneficiada pelos altos preços do petróleo. Logo, é possível afirmar que o bloco era dependente tanto da figura de Hugo Chávez quanto do petróleo venezuelano (RIGGIROZZI e TUSSIE, 2012) 
uma vez que com o passar dos anos, com o fim do governo Chávez e com a crise econômica venezuelana, o bloco parece despencar em produtividade de políticas e relevância regional.

Já a criação da Unasul, uma vez tendo revelado os distintos interesses estratégicos que cada um desses países possuía para o bloco e suas respectivas inserçôes regionais (BARNABÉ, 2012), avançou em matérias de política de defesa comum, difusão de ideais democráticos na região e em concerto político entre os governos da regiāo (BATISTA e ALBUQUERQUE, 2017) - avanços consideráveis em direção do norte autonomista (GRANATO, 2015). Contudo, o referido bloco ainda deve dar provas de que será um organismo efetivo em um cenário mediado pela influência de agendas, interesses e visóes extrarregionais e que fazem de um processo mais amplo que envolve a competição interestatal capitalista (FIORI, 2013).

Além disso, com a recente virada ideológica na região, com o retorno de governos de centro-direita ${ }^{5}$, e por entendermos que a integraçáo regional se refere a uma convergência de interesses ideológicos (PETERSEN e SCHULZ, 2018), propostas como a ALBA e a Unasul enfrentam desafios diferentes no novo contexto. Por um lado, os países membros da ALBA não compóem a virada ideológica, mantendo governos de esquerda e radicais no que tange a contestaçáo à influência da potência hemisférica. Contudo, como já mencionamos, além da dependência do petróleo venezuelano, que já não possui o preço de dez anos atrás, a ALBA possui hoje dois países em severas crises políticas e sociais internas, Venezuela e Nicarágua. Por mais que a integração possa ser utilizada como instrumento de legitimaçáo das agendas domésticas, nem o governo Maduro nem o governo Ortega entendem a ALBA como lócus salvador de suas instabilidades.

Já a Unasul enfrenta diretamente a perda de convergência de interesses e de ideologia em seu futuro incerto. O anúncio, nos primeiros meses de 2018, da auto-

\footnotetext{
${ }^{5}$ A virada ideológica refere-se a um processo de mudança dos governos de centro-esquerda que tinham emergido no início dos anos 2000. Inicia-se com a ruptura do governo de Fernando Lugo (movimento estigmatizado como golpe de Estado pelo presidente derrubado) e a ascensão de Horácio Cartes no Paraguai, se aprofunda com a eleiçâo de Maurício Macri na Argentina em 2014, e se consolida com o governo de Michel Temer no Brasil, que assume após o golpe a Dilma Rousseff (JINKINGS, DORIA e CLETO, 2016). Todos esses casos correspondem a governos que ascendem com a agenda de reformas macroeconômicas voltadas para a liberalizaçáo da economia e do comércio como prioridades. Dessa forma, tais casos possuem objetivos distintos também para a integração regional, entendendo essa como instrumento para fazer valer suas agendas domésticas.
} 
suspensão de seis países do bloco ${ }^{6}$, todos de governos de centro-direita, reflete a incapacidade do organismo regional de se manter com o objetivo de autonomia e desenvolvimento, de concerto político e de defesa da democracia como princípio universal, valores presentes no Tratado Constitutivo do bloco (BATISTA, 2018).

Ademais do retorno da agenda autonomista nos processos de cooperaçáo regional dos anos 2000, o paradigma liberal não se encontrou superado. A criação da Aliança do Pacífico em 2011, que unificou os países que não participaram da "onda rosa” (Chile, Colômbia, Peru e México), é exemplo de uma proposta liberalizante do comércio intra-regional, elogiada pelos organismos internacionais que outrora eram considerados os gurus econômicos da regiáo (Fundo Monetário Internacional e Banco Mundial), e voltada para a expansão comercial ao Leste Asiático. No momento de sua criação, apresentava $35 \%$ do PIB da região e concentra metade do comércio da América Latina com o resto do mundo (JESUS, 2013). Além de seguir uma tendência do comércio mundial e virar-se à China e à Ásia, os países-membro possuem interesse estratégico no bloco, como o retorno do México à regiáo sulamericana (ZICCARDI, 2014).

Por fim, na re-orientaçáo do Mercosul rumo a um processo mais produtivo e social, tornou-se claro que os valores de autonomia e desenvolvimento guiavam a política de integraçáo regional de Argentina e do Brasil, uma vez que buscou-se ampliar a participação social, democratizar a formulação da agenda do bloco e estender a integração proposta para os campos da coordenação política, e da integração produtiva, cultural e social (GRANATO, 2015). Cabe esclarecer aqui que a noçáo de desenvolvimento nesta nova fase mostra-se muito mais complexa do que no passado (vinculada ao crescimento econômico), cedendo espaço perante a ideia de um processo de expansão das liberdades reais de que desfrutam os cidadãos (SEN, 2010), devendo ser socialmente includente, ambientalmente sustentável e economicamente sustentado (SACHS, 2005) ${ }^{7}$. Contudo, os avanços reais dessa nova agenda são passíveis de questionamento durante a própria vigência dos governos progressistas que a propuseram. A não superação do paradigma liberal é também fundamentada nos avanços reais que o Mercosul apresentou - ou deixou de apresentar. A manutenção da estrutura organizacional intergovernamental e o descompasso entre o discurso e realidade das novas instâncias de participação

\footnotetext{
${ }^{6}$ Argentina, Brasil, Chile, Colômbia, Paraguai e Peru.

${ }^{7}$ Uma crítica a esta abordagem pode ser encontrada em Bonente (2014) e Bonente e Medeiros (2016).
} 
(Parlasul; Foro Consultivo de Municípios, Estados Federados, Províncias e Departamentos; Unidade de Apoio à Participação Social) são críticas que devem ser feitas a esse respeito (GRANATO e BATISTA, 2018b).

Durante os primeiros anos desse milênio, parece não ser possível falar em desenvolvimento na América do Sul sem referenciar a influência de grandes potências econômicas nos processos de cooperação da região. Ao mesmo tempo em que a ausência de uma agenda dos Estados Unidos para a América Latina nesse período possibilitou a criação de espaços regionais e hemisféricos sem a presença da potência hegemônica (TULCHIN, 2016), permitindo o retorno no discurso autonomista na integração regional, a China é peça fundamental na política da América do Sul na virada do milênio. Ainda que não componha os organismos regionais, o crescimento chinês impactou diretamente o desenvolvimento da região: durante o boom econômico do gigante oriental, as economias latino-americanas cresceram 3,6\% por ano, a melhor média desde o período desenvolvimentista de 1930-1982 (GALLAGHER, 2016). Ou seja, com o distanciamento da influência financeira neoliberal estadunidense dos anos 1990, a sede chinesa pelos recursos naturais da regiáo retomou as taxas de crescimento econômico.

O que demonstram Carmo e Pecequilo (2016) é que a presença chinesa na economia latino-americana (se tornando principal parceira comercial de países-chave no quebra-cabeça da política regional, como Brasil, Chile, Colômbia e Venezuela), impacta diretamente os processos de cooperaçáo regional. Nas discussóes sobre a liderança brasileira na região (ou a ausência desse papel altivo), é o nome da China que desponta como incentivadora/interessada em propostas de infraestrutura, integração de malhas produtivas e aproximação entre blocos econômicos, a exemplo da aproximação entre Mercosul e Aliança do Pacífico. Em documento recente, a CEPAL (2018a) defende a aproximação entre os blocos, argumentando que os paísesmembros de ambas as propostas concentram $80 \%$ da populaçáo, $85 \%$ do comércio intra-regional e $90 \%$ de investimento estrangeiro direto. Contudo, apenas $15 \%$ do comércio exterior dos países da América Latina são intra-regionais. Quando a CEPAL (2018b) aponta que a liberalização comercial entre Mercosul e Aliança do Pacífico e o consequente aumento do fluxo comercial intra-regional são os meios de redução de desigualdade social, o que se percebe é o retorno evidente do paradigma liberal na agenda de cooperação regional da América Latina.

Assim, o que serve como alerta para os ciclos seguintes da integração na América do Sul é que os contextos nacionais, regional e internacional já são outros. A dependência do apetite chinês pelos recursos naturais latino-americanos pode ser 
danosa quando essa potência oriental modifica os objetivos de sua economia e passa a comprar menos commodities na região (TULCHIN, 2016). A tendência é de manutenção da presença chinesa na regiáo, mas não mais em termos vultuosos como foi nos primeiros quinze anos dos anos 2000. Por outro lado, o afastamento estadunidense sob a égide protecionista do presidente Donald Trump, o que poderia significar manutenção da brecha estrutural para uma política externa autonomista, esbarra nas conjunturas domésticas dos países da regiáo. A crise do período de governos progressistas na regiáo tem favorecido profundas mudanças nos projetos e agendas nacionais e sociais que orientaram as políticas estatais em muitos países sulamericanos a partir dos anos 2000. Dentre elas, a integraçáo regional, agora mais afinada com a perspectiva neoliberal do período anterior, e mais alinhada aos países da América do Norte, da Ásia e da Europa.

\section{À guisa de conclusão}

Através do presente trabalho buscamos discutir quais os frequentes usos da integração regional para os países sul-americanos. Em uma retrospecção histórica, torna-se evidente que a integraçáo tenha sido pensada sempre como ampliação da agenda doméstica de cada governo nacional. Da segunda metade do século XX, a integração foi em especial entendida como instrumento de desenvolvimento econômico e de superação de entraves típicos da periferia do sistema internacional. Com esse fim, contudo, distintos foram os meios para perseguição do desenvolvimento. Baseando-nos em uma consolidada tradição intelectual nas ciências sociais, sistematizamos um conjunto de aportes teóricos que julgamos essenciais para entender a questão da integração regional - e suas orientaçóes -, em um contexto de um sistema interestatal capitalista em constante evolução e reconfiguração. Valendonos dos aportes mencionados, analisamos a trajetória dos ciclos da integração regional na América do Sul em particular.

Assim como a nível conceitual é possível observar a disputa entre o princípio de livre comercio/lógica de mercado e os ideais de desenvolvimento e autonomia existente nos debates teóricos, na prática dos regionalismos, como vimos, não foi diferente. Ou seja, dependendo dos objetivos dos Estados partes, a integração pode, ainda que sempre em um contexto capitalista e dependente, refletir uma aproximação pró-mercado exclusiva ou buscar o desenvolvimento econômico a partir da consolidação da autonomia política nacional e regional, internalizando no processo determinadas demandas sociais. 
Remetendo o início das propostas de integração ao ideal de Simón Bolívar de uma América Latina unida e integrada, nota-se como desde o princípio a integração foi entendida como meio para perseguir interesses internos. Assim, enquanto naçóes recém-independentes a integração seria funcional à consolidação dos Estados emergentes. Como resultado da Guerra do Paraguai, a problemática regional passa a ser coordenaçáo da segurança externa e das defesas nacionais, e para isso também a cooperação regional foi considerada. Após a Segunda Guerra mundial e com a crescente preocupação com o subdesenvolvimento periférico e a ampliação do gap entre periferia e centro, o desenvolvimentismo torna-se a orientação dos Estados latino-americanos e a integração regional adentra um período de florescimento intelectual. É como instrumento para o desenvolvimento que esta será especialmente considerada nesse período, não tendo sido tão fértil no campo das propostas práticas. É somente em um contexto de prevalência do princípio mercantil, no ciclo do regionalismo aberto dos anos 1990, que propostas como a do Mercosul são criadas e, por mais que tenha observado instabilidade ainda na década de sua criaçáo, retrospectivamente podemos caracterizar como bem-sucedidas ao que se propunha.

$\mathrm{Na}$ virada dos anos 2000, a agenda liberal da integração foi cedendo espaço para uma retomada dos valores de desenvolvimento e autonomia anteriormente elaboradas nas décadas de 1960 e 1970. Apesar dessa "mudança de visão" na forma de conceber o Mercosul, e refletida também na criação dos blocos da ALBA e da Unasul, as políticas consequentes parecem não ter tido força suficiente para reorientar a integração no continente e consolidar o novo modelo. Ao assistirmos uma nova virada ideológica na região, as propostas de integração revestir-se-ão da "carapuça" neoliberal (para o caso do Mercosul) ou estarão fadados aos entraves (como a ALBA e a Unasul). Os avanços reais da década anterior, além de poucos, são facilmente revertidos a partir da nova agenda dos governos de centro-direita. Como não existem garantias que uma mesma convergência ideológica perdure décadas, a integração regional latino-americana seguirá a mercê da direção para onde o vento estiver soprando, em um ir e vir que náo parece muito promissor para que o barco avance.

- Leonardo Granato é Doutor em Economia Política Internacional pela Universidade Federal do Rio de Janeiro (UFRJ). Professor do Programa de Pós-Graduação em Ciência Política da Universidade Federal do Rio Grande do Sul (UFRGS). E-mail: leonardo.granato@ ufrgs.br. 


\section{- Ian Rebouças Batista é Mestrando do Programa de Pós- Graduação em Ciência Política da UFRGS. E-mail: reboucas.ian@, gmail.com.}

\section{Referências}

ARAGÁO, José M. Integración latinoamericana y desarrollo nacional. Revista de la Integración, [s./v.], n. 4, p. 152-180, 1969.

BARNABÉ, Israel R. Del ABC al ABV: El eje Argentina, Brasil y Venezuela en la integración de América del Sur. Cuadernos sobre Relaciones Internacionales, Regionalismo y Desarrollo, v. 7, n. 14, p. 9-26, 2012.

BATISTA, Ian Rebouças. Unasul estancada. Vox Magister. 2018. Disponível em: <http://voxmagister.com.br/2018/04/24/unasul-estancada>. Acesso em: 20 maio 2018.

BATISTA, Ian Rebouças; ALBUQUERQUE, Rodrigo Barros. 2017. Multilateralismo intergovernamental: a Unasul como concerto político. In: 41 ${ }^{\circ}$ Encontro Anual da Associação Nacional de Pós-Graduação e Pesquisa em Ciências Sociais (ANPOCS), 23 a 27 out. 2017.

BERNAL-MEZA, Raúl. La doctrina de la autonomía: realismo y propósitos. Su vigencia. In: BRICEÑO, José; SIMONOFF, Alejandro (Orgs.). Integración y cooperación regional en América Latina: una relectura a partir de la teoría de la autonomía. Buenos Aires: Biblos, 2015, p. 95-120.

BONENTE, Bianca I. Desenvolvimento em Marx e na teoria econômica: por uma crítica negativa do desenvolvimento capitalista. Marx e o Marxismo, v. 2, n. 3, p. 275-286, 2014.

BONENTE, Bianca I; MEDEIROS, João L. Desenvolvimento como ausência de liberdade: Marx contra Sen. Revista da Sociedade Brasileira de Economia Política, [s./v.], n. 45, p. 38-63, 2016.

CARDOSO, Fernando Henrique; FALETTO, Enzo. Dependência e Desenvolvimento na América Latina: Ensaio de interpretação sociológica. Rio de Janeiro: Zahar, 1973.

CARMO, Corival Alves do; PECEQUILO, Cristina Soreanu. Brazil and the regional leadership vacuum: the chinese-american advance (2011-2016). Austral: Brazilian Journal of Strategy \& International Relations, v. 5, n. 9, p. 53-73, 2016.

CEPAL. El mercado común latinoamericano. Santiago de Chile: Naciones Unidas, 1959. 1994. El regionalismo abierto en América Latina y el Caribe. Santiago de Chile: Naciones Unidas,

. La convergencia entre la Alianza del Pacifico y el Mercosur. Enfrentando juntos un escenario mundial desafiante. Santiago de Chile: Naciones Unidades, 2018a.

. A ineficiência da desigualdade. Santiago de Chile: Naciones Unidades, $2018 \mathrm{~b}$.

FERRER, Aldo. Hechos y ficciones de la globalización: Argentina y el Mercosur en el sistema internacional. Buenos Aires: Fondo de Cultura Económica, 2006. 
FIORI, José Luis. O Brasil e seu 'entorno estratégico' na primeira década do século XXI. In: SADER, Emir (Org.) 10 anos de governos pós-neoliberais no Brasil: Lula e Dilma. São Paulo; Rio de Janeiro: Boitempo; FLACSO Brasil, 2013, p. 31-51.

FONSECA, Pedro C. D. As origens e as vertentes formadoras do pensamento cepalino. Revista Brasileira de Economia, v. 54, n. 3, p. 333-358, 2000.

FURTADO, Celso. Teoria e Política do Desenvolvimento Econômico. São Paulo: Companhia Editorial Nacional, 1967.

Pequena Introdução ao Desenvolvimento: Enfoque Interdisciplinar. São Paulo: Editorial Nacional, 1980.

GALLAGHER, Kevin P. The China Triangle. New York: Oxford University Press, 2016.

GARCÍA DELGADO, Daniel, CHOJO, Martín. Desarrollo e integración regional. Hacia un modelo productivo social. In: GARCÍA DELGADO, Daniel; NOSETTO, Luciano (Comp.) El desarrollo en un contexto posneoliberal: hacia una sociedad para todos. Buenos Aires: Ediciones CICCUS, 2006, p. 119-137.

GRACIARENA, Jorge. El Estado latinoamericano en perspectiva. Figuras, crisis, prospectiva. Pensamiento Iberoamericano, [s./v.], n. 5, p. 39-74, 1984.

GRANATO, Leonardo. Brasil, Argentina e os rumos da integraçâo: o Mercosul e a Unasul. Curitiba: Appris, 2015.

GRANATO, Leonardo; BATISTA, Ian Rebouças. Heterogeneidade estrutural nas relaçóes internacionais da América Latina: um olhar através dos paradigmas de integração regional. Cadernos PROLAM/USP, v. 16, n. 31, p. 5-29, 2017.

Estado, autonomia e integração regional na América Latina. Latinoamérica: Revista de Estudios Latinoamericanos, [s./v.], n. 66, p. 261-285, 2018a.

Mercosul à prova: estratégias e limites da integração regional periférica. Revista Brasileira de Políticas Públicas e Internacionais, v. 3, n. 1, p. 230-253, 2018 b.

HARVEY, David. Organización para la transición anticapitalista. Crítica y emancipación Revista Latinoamericana de Ciencias Sociales, v. 1, n. 4, p. 167-193, 2010.

ILPES. La brecha comercial y la integración latinoamericana. México: Siglo Veintiuno, 1967.

JAGUARIBE, Helio. Dependencia y Autonomía en América Latina. In: JAGUARIBE, Helio; FERRER, Aldo; WIONCZEK, Miguel; SANTOS, Theotonio dos (Orgs.). La dependencia políticoeconómica de América Latina. Buenos Aires: Siglo Veintiuno; CLACSO, 1973, p. 1-85.

JINKINGS, Ivana; DORIA, Kim; CLETO, Murilo (Org.) Por que gritamos Golpe? Para entender o impeachment e a crise política no Brasil. São Paulo: Boitempo, 2016.

JESUS, Samuel de. A Aliança do Pacífico e a importância das relaçôes bilaterais entre Brasil e Peru. Mundorama. 2013. Disponível em: <http://mundorama.net/2013/09/06/a-alianca-do-pacifico-e-aimportancia-das-relacoes-bilaterais-entre-brasil-e-peru-por-samuel-de-jesus $>$. Acesso em: 28 nov. 2014.

KAPLAN, Marcos. El Estado en el Desarrollo y la Integración de América Latina. Ensayos. Caracas: Monte Ávila Editores, 1969.

. El Estado y la teoría política y constitucional en América Latina. In: GONZÁLEZ CASANOVA, Pablo (Coord.) El Estado en América Latina: Teoría y Práctica. México: Universidad de las Naciones Unidas; Siglo Veintiuno, 1990, p. 70-107.

LANÚS, Juan A. La integración económica de América Latina. Buenos Aires: Juárez Editor, 1972. 
LECHNER, Norbert. Presentación. In: LECHNER, Norbert. (Ed.) Estado y Política en América Latina. México: Siglo Veintiuno Editores, 1981, p. 7-24.

MATTEI, Lauro. Gênese e agenda do atual desenvolvimentismo brasileiro. Revista de Economia Política, v. 33, n. 1, p. 41-59, 2013.

MINDLIN, José E. O desenvolvimento brasileiro e a crise da ALALC. Revista de Administração de Empresas, v. 13, n. 2, p. 75-80, 1973.

MUHR, Thomas. Counter-hegemonic regionalism and higher education for all: Venezuela and the ALBA. Globalisation, Societies and Education, v. 8, n. 1, p. 39-57, 2010.

. Venezuela and the ALBA: Counter-Hegemony, Geographies of Integration and Development and Higher Education for All. Saarbrücken: VDM, 2011.

O’DONNELL, Guillermo; LINCK, Delfina. Dependencia y Autonomía. Formas de dependencia y estrategias de liberación. Buenos Aires: Amorrortu, 1973.

OSTRY, Jonathan D.; LOUNGANI, Prakash; FURCERI, Davide. Neoliberalism: Oversold? Finance and Development, v. 53, n. 2, p. 38-41, 2016.

PETERSEN, Mark; SCHULZ, Carsten-Andreas. Setting the regional agenda: A critique of posthegemonic regionalism. Latin American Politics and Society, v. 60, n. 1, p. 102-127, 2018.

PUIG, Juan Carlos. Doctrinas internacionales y autonomía latinoamericana. Caracas: IAEAL/Universidad Simón Bolívar, 1980.

- Integración y autonomía de América Latina en las postrimerías del siglo XX. Integración Latinoamericana, [s./v.], n. 109, p. 40-62, 1986.

RIGGIROZZI, Pía; TUSSIE, Diana. The Rise of Post-Hegemonic Regionalism in Latin America. In: RIGGIROZZI, Pía; TUSSIE, Diana (Orgs.) The Rise of Post-Hegemonic Regionalism. The case of Latin America. London: Springer, 2012, p. 1-16.

RODRIGUEZ, Octavio. O pensamento da CEPAL: Síntese e crítica. Novos Estudos CEBRAP, [s./v.], n. 16, p. 8-28, 1986.

SACHS, Ignacy. Desenvolvimento e cultura. Desenvolvimento da cultura. Cultura do desenvolvimento. Organizaçóes \& Sociedade, v. 12, n. 33, p. 151-165, 2005.

SADER, Emir. El nuevo topo: los caminos de la izquierda latinoamericana. Buenos Aires: Siglo XXI Editores; CLACSO, 2010.

SARAIVA, Miriam G. Encontros e Desencontros: O lugar da Argentina na política externa brasileira. Belo Horizonte: Fino Traço, 2012.

SARTI, Ingrid. Desafios à Esquerda. Notas sobre a Integração em tempos de crise. In: SIERRA, Gerónimo de (Org.) Los progresismos en la encrucijada: Argentina, Bolivia, Brasil, Uruguay, Venezuela. Montevideo: Universidad de la República; Facultad de Ciencias Sociales, 2017, p. 99110.

SCHARPF, Fritz W. Negative and Positive Integration in the Political Economy of European Welfare States. In: MARKS, Gary; SCHARPF, Fritz; SCHMITTER, Philippe; STREECK, Wolfgang. Governance in the European Union. Thousand Oaks: Sage Publications, 1996, p. 15-39.

SEN, Amartya. Desenvolvimento como liberdade. São Paulo: Companhia das Letras, 2010.

SOARES DE LIMA, Maria Regina. Relaçôes interamericanas: a nova agenda sul-americana e o Brasil. Lua Nova, [s./v.], n. 90, p. 167-201, 2013. 
SOARES, Claudia L. B. Para uma aproximação ao desdobramento histórico do conceito de desenvolvimento econômico e seus indicadores. In: SUAREZ CRUZ, Clara A.; CORAZZA, Gentil; SOUZA, Nilson A. de (Org.). América Latina: Olhares e Perspectivas. Florianópolis: Insular, 2016, p. 195-218.

SUNKEL, Osvaldo; PAZ, Pedro. El subdesarrollo latinoamericano y la teoría del desarrollo. México: Siglo Veintiuno, 1970.

TORRES RIVAS, Edelberto. Estado y Sociedad en Prebisch. Comercio Exterior, v. 37, n. 6, p. $457-$ 463, 1987.

TULCHIN, Joseph S. Latin America in International Politics: Challenging US hegemony. Boulder: Lynne Rienner Publishers, 2016.

VEIGA, Pedro da Motta; RIOS, Sandra. O regionalismo pós-liberal, na América do Sul: origens, iniciativas e dilemas. Santiago de Chile: CEPAL, 2007.

VIEIRA, Jeferson de Castro. As experiências de integração da ALALC e ALADI. Revista de Estudos e Pesquisas sobre as Américas, v. 9, n. 1, p. 27-56, 2015.

VISENTINI, Paulo. O Brasil, o Mercosul e a integração da América do Sul. Revista de Estudos e Pesquisas sobre as Américas, v. 1, n. 1, p. 82-94, 2007.

ZICCARDI, Natalia S. The Mexican Agenda in Latin America: The Pacific Alliance. Anuario de la Integración Regional de América Latina y el Gran Caribe, [s./v.], n. 10, p. 421-436, 2014.

Texto recebido em 11 de junho de 2018. Aprovado em 10 de agosto de 2018. 